\title{
Acetylation of C-terminal lysines modulates protein turnover and stability of Connexin-32
}

\author{
Sarah R. Alaei ${ }^{1}$, Charles K. Abrams², J. Chloë Bulinski ${ }^{3}$, Elliot L. Hertzberg ${ }^{3}$ and Mona M. Freidin ${ }^{2 *}$ (D)
}

\begin{abstract}
Background: The gap junction protein, Connexin32 (Cx32), is expressed in various tissues including liver, exocrine pancreas, gastrointestinal epithelium, and the glia of the central and peripheral nervous system. Gap junction-mediated cell-cell communication and channel-independent processes of $\mathrm{C} \times 32$ contribute to the regulation of physiological and cellular activities such as glial differentiation, survival, and proliferation; maintenance of the hepatic epithelium; and axonal myelination. Mutations in Cx32 cause X-linked Charcot-Marie-Tooth disease (CMT1X), an inherited peripheral neuropathy. Several CMT1X causing mutations are found in the cytoplasmic domains of $\mathrm{C} \times 32$, a region implicated in the regulation of gap junction assembly, turnover and function. Here we investigate the roles of acetylation and ubiquitination in the C-terminus on $\mathrm{C} \times 32$ protein function. $\mathrm{C} \times 32$ protein turnover, ubiquitination, and response to deacetylase inhibitors were determined for wild-type and C-terminus lysine mutants using transiently transfected Neuro2A (N2a) cells.

Results: We report here that Cx32 is acetylated in transfected N2a cells and that inhibition of the histone deacetylase, HDAC6, results in an accumulation of $\mathrm{C} \times 32$. We identified five lysine acetylation targets in the C-terminus. Mutational analysis demonstrates that these lysines are involved in the regulation of $\mathrm{C} \times 32$ ubiquitination and turnover. While these lysines are not required for functional Cx32 mediated cell-cell communication, BrdU incorporation studies demonstrate that their relative acetylation state plays a channel-independent role in Cx32-mediated control of cell proliferation.
\end{abstract}

Conclusion: Taken together these results highlight the role of post translational modifications and lysines in the C-terminal tail of $\mathrm{C} \times 32$ in the fine-tuning of $\mathrm{C} \times 32$ protein stability and channel-independent functions.

Keywords: Gap junctions, Acetylation, Ubiquitination, Cell-cell communication, Connexin

\section{Background}

Connexins are a family of 21 homologous integral membrane proteins that form cell-cell channels, known as gap junctions (GJ) [1-3]. GJ provide a low resistance pathway for the diffusion of small molecules and ions between coupled cells [4]. Recent data also suggest connexin involvement in channel-independent processes including cell growth, autophagosome formation, cell adhesion, cell motility and cell migration [5-10]. The C-termini of different connexins vary substantially in length and in their capacity to mediate interactions with the cytoskeleton [11-13], and junctional complexes [12, 14]. The C-terminal sequences of connexins have also been implicated in voltage (reviewed in [15]), $\mathrm{pH}$ and chemical

\footnotetext{
* Correspondence: mfreidin@uic.edu

${ }^{2}$ Department of Neurology \& Rehabilitation, University of Illinois at Chicago, Chicago, IL 60612, USA

Full list of author information is available at the end of the article
}

[16-18], gating of different GJ channels. C-terminal truncation of GJA1 (Connexin43; Cx43) does not alter the ability to form functional gap junctions, but does alter trafficking to the plasma membrane and gap junction plaque formation to indirectly reduces overall GJ-mediated cell-cell communication [19-21]. Cytoplasmic domains in several connexins, including $\mathrm{Cx} 43$ and GJB1 (Connexin32; Cx32), have also been implicated in GJ-independent processes, such as regulation of cell growth and gene expression [22-24].

The cytoplasmic domains of some connexins are subject to post translational modifications such as phosphorylation, ubiquitination, and acetylation, though relatively little is known about how these modifications impact function. To date, most investigations of connexin post translational modifications have focused on Cx43. Phosphorylation modulates Cx43-mediated GJ communication through the modulation of channel 
closure [25], accretion in GJ plaques [25, 26], removal from the plasma membrane, and subsequent protein turnover [27, 28]. Ubiquitinated Cx43 is targeted for degradation by the proteasomal [29,30], endo-lysosomal [31], and autophagosomal [32] pathways, depending on its subcellular localization, specific ubiquitin moieties and modification sites. Acetylation of $\mathrm{Cx} 43$ has also been identified as a negative regulator of plasma membrane localization [33], although it is unclear if it influences Cx43 insertion or degradation. Despite having been identified as a phosphoprotein over 20 years ago [34], considerably less is known about the abundance and functions of any post-translational modifications of $\mathrm{Cx} 32$.

Cx32 is widely expressed in various tissues including liver, exocrine pancreas, gastrointestinal epithelium, and the glia of the central and peripheral nervous system. Mutations in Cx32 cause X-linked Charcot-Marie-Tooth disease (CMT1X), an inherited peripheral neuropathy [35, 36]. CMT1X associated mutations result in diverse alterations in Cx32 expression and function, including defects in trafficking and GJ formation and gating [35, 37-39]. More than 300 CMT1X mutations have been identified covering most of the Cx32 gene (http://www.molgen.ua.ac.be/CMTMutations). CMT1X mutations in the transmembrane and cytoplasmic loop regions prevent the assembly of GJ in the plasma membrane CMT1X [40-42]. Mutations in the $\mathrm{C}$-terminus of $\mathrm{Cx} 32$ result in functional alterations but do not prevent GJ assembly [38].

The C-terminus of $\mathrm{Cx} 32$ has also been implicated in processes such as $\mathrm{Ca}^{2+}$ regulated gap junctional gating [43] and the modulation of cellular proliferation [44]. Post-translational modifications have been identified in the C-terminus of Cx32, but their physiological significance is poorly understood $[45,46]$. In this study, we focus on the role of post translational modifications of C-terminal lysine residues in the modulation of Cx32 protein stability and function. We report here that Cx32 is acetylated and have identified five lysines in the C-terminus as likely acetylation sites. Further, we demonstrate that these lysines are involved in the regulation of Cx32 protein stability, ubiquitination, and turnover. Finally, while the acetylation state of these lysines are not directly involved in modulating Cx32 GJ communication, we show their relative acetylation state plays a role in Cx32-mediated control of channel-independent cellular processes such as cell proliferation.

\section{Methods}

\section{Cell lines}

Cell lines were obtained from American Type Culture Collection (ATCC, Manassas, VA). Cultures were maintained in DMEM supplemented with $10 \%$ FBS at $37{ }^{\circ} \mathrm{C}$ and $5 \% \mathrm{CO} 2$, at $100 \%$ humidity. Unless otherwise noted, all experiments were performed using connexin-deficient
Neuro-2a (N2a) cells (ATCC \#CCL-131). N2a cells were used for subsequent experiments to maintain consistency between electrophysiological, microscopic, and biochemical analyses. HeLa cells (ATCC \#CCL-2) were used in preliminary experiments (Fig. 1a, b).

\section{Plasmids}

Rat Cx32 cDNA subcloned into pIRES2EGFP. To generate Myc/His-tagged constructs, rat $\mathrm{Cx} 32$ cDNA was cloned into BamHI/ApaI sites of pcDNA3.1/Myc-His A. The $K \rightarrow R$ and $K \rightarrow Q$ mutations were generated using Genetailor site-directed mutagenesis kit, as per manufacturer's recommendations (Invitrogen/Life Technologies) and subcloned into relevant vectors. pIRES2EGFP-Cx32 was used for imaging, BrdU incorporation, and electrophysiology experiments. pcDNA3.1-Cx32-Myc/His was used in all other experiments to facilitate isolation of Cx32 using the Myc and His epitope tags.

\section{Western blotting}

Total protein from N2a cells was harvested in PBS supplemented with $1 \%$ Triton-X 100. Samples were denatured $30 \mathrm{~min}$ at room temperature following addition of standard Laemmli SDS-PAGE loading buffer to limit aggregate formation $[47,48]$. Proteins were separated on $10 \%$ polyacrylamide denaturing gels and transferred to nitrocellulose membranes. Blocking and antibody dilution was carried out in PBS containing 2\% BSA and 0.05\% Tween.

Western blots were probed with mouse anti-Cx32 clone 7c6.7c (Elliot Hertzberg) 1:1000, rabbit anti-Myc tag (AbCam) 1:2000, rabbit anti-acetylated proteins (Ack, Cell Signaling Technologies) 1:1000, mouse anti-ubiquitinated proteins clone P4G7 (Covance)1:200, and mouse anti- $\beta$-tubulin clone 3F3-G2 at 1:2000. Goat anti-rabbit IRdye 800 and goat anti-mouse IRdye700 secondary antibodies (LiCor) were used for detection and digital images were obtained with the Odyssey imaging system (LiCor).

Western blots were also analyzed using GelQuant.NET software (http://biochemlabsolutions.com/GelQuantNET.html), normalizing to actin or $\beta$-tubulin signal, where appropriate. Fold change was calculated relative to untreated WT signals for each probe.

\section{Drugs and other chemicals}

TubastatinA (TubA, Chemie Tek) and Trichostatin A (TSA, Sigma) were dissolved in DMSO (1 $\mathrm{mM}$ and $20 \mu \mathrm{M}$, respectively) prior to further dilution in medium. All other chemicals were obtained from Sigma Aldrich, unless otherwise indicated. Cells were treated with $20 \mu \mathrm{M}$ TubA for $3 \mathrm{~h}$, unless otherwise indicated.

\section{Transfections}

N2a cells were transiently transfected using Lipofectamine LTX (Invitrogen/Life Technologies) according to 


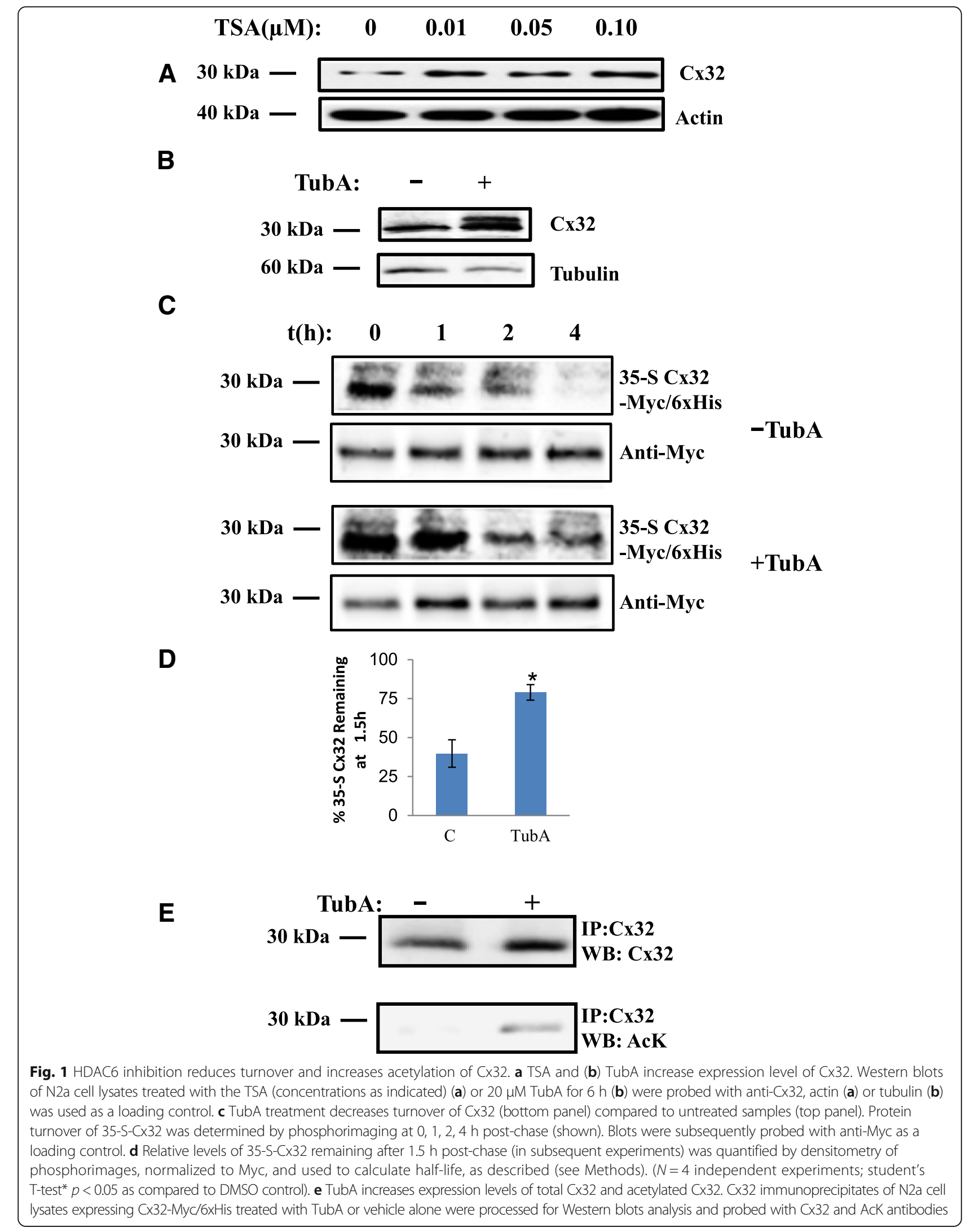


the manufacturer's instructions. Antibiotic-free media was used for transfection reactions and all subsequent culture steps. Transfected cells were re-seeded on to glass coverslips at 12-16 h post-transfection for electrophysiology and immunofluorescence experiments.

\section{Immunofluorescence and BrdU incorporation}

Transfected cells were grown overnight after seeding on to glass coverslips, treated as described, and fixed 15-min at room temperature with Histochoice (Amresco). Coverslips were washed with PBS supplemented with $0.05 \%$ Tween. Blocking and antibody dilutions were carried out in PBS supplemented with $0.05 \%$ Tween and $2 \%$ BSA. Cx32 was probed with mouse anti-Cx32 clone 7C6.6 (1:1200). Signal was detected with Alexa-Fluor-conjugated secondary antibodies (Molecular Probes) and the coverslips were mounted using ProLong Gold plus DAPI (Molecular Probes) or Fluoromount (Invitrogen) with DAPI.

For proliferation studies, cultures were treated with BrdU (10 $\mu \mathrm{M}$, Molecular Probes) overnight and fixed with Histochoice as described. Immunofluorescent detection of Cx32 preceded denaturation and immunolabeling for BrdU. Following immunolabeling for Cx32, samples were denatured 30 min with $2 \mathrm{~N} \mathrm{HCl}$ in $0.1 \%$ Triton-X-100, neutralized with $0.2 \mathrm{M}$ Borate buffer, $\mathrm{pH} 9.0$ and washed with PBS. The samples were then processed for BrdU incorporation using monoclonal anti-BrdU (LabVision/ ThermoFisher;1:150) immunofluorescence.

\section{Imaging}

A Zeiss LSM 700 confocal microscope system was used to obtain Z-stacks at $63 \times$ magnification. All images were obtained with a pinhole size of 1 airy unit. Laser power, filter settings, beam splitter, and scan mode were the same for all images. Confocal imaging was used to obtain Z-stacks of 0.29 um slices (63X). Images shown are maximum intensity projections of 5 slices that were most in focus at points of cell-cell contact. Integrated fluorescence values were obtained from background subtracted images using the Cell Scoring and Multi-Wavelength Cell Scoring applets in Metamorph 7 image analysis software (Molecular Devices). Thresholds were determined using negative control images and cellular integrated fluorescence constituted less than $10 \%$ of positively scored cells.

\section{Cell lysate preparation for immunoprecipitation and $\mathrm{Co} 2+$ purification}

Cells were scraped into PBS and collected by low speed centrifugation. The cell pellets were lysed in PBS supplemented with $1 \%$ Triton-X 100 and protease inhibitors (LB). 20\% SDS was added to a final concentration of $1.2 \%$ and incubated on ice $30 \mathrm{~min}$ to solubilize gap junctions [49]. For immunoprecipitation, sufficient LB was added to dilute SDS to a final concentration of $0.4 \%$.
The lysate was passed through a 26.5-gauge needle and centrifuged to remove debris. For His-tagged Cx32, Hispur-Co2+ coated agarose beads (Pierce) were added to the cleared supernatant and incubated as per manufacturer's suggestions. His-tagged Cx32 was eluted with lysis buffer containing $300 \mathrm{mM}$ imidazole, as per manufacturer's suggestions. Where noted, samples were immunoprecipitated using an affinity purified rabbit polyclonal to $\mathrm{Cx} 32$ raised to $\mathrm{C}$-terminal peptides (E. Hertzberg) with Protein G-agarose beads (Pierce/ThermoFisher) and eluted as per manufacturer's suggestions.

\section{5-S met/Cys pulse-chase assay}

Cells were transfected $48 \mathrm{~h}$ prior to experiments. Each experimental sample consisted of confluent $10 \mathrm{~cm}$ plate of transfected cells. For +/- TubA experiments, cells were pretreated with $20 \mu \mathrm{M}$ TubA or DMSO for $16 \mathrm{~h}$ prior to Met/Cys pulse. Cells were rinsed with $3 \times 4 \mathrm{ml}$ PBS and then starved in DMEM lacking serum, methionine, and cysteine for $1 \mathrm{~h}$. The 35-S-Met/Cys pulse was carried out for $20 \mathrm{~min}(+/-$ TubA experiments) or five minutes (WT versus $5 \mathrm{R}$ or $5 \mathrm{Q}$ ).

Radioactive pulse media containing $50 \mathrm{mCi} / \mathrm{ml}$ of 35-S-Met/Cys (Expre35-S35-S labeling mix, Perkin Elmer), $10 \%$ FBS, and Met/Cys-free DMEM was used for each sample. After radioactive pulse, each plate was washed thrice with PBS and chased with complete DMEM with an additional $20 \mathrm{mM}$ Met/Cys for indicated times.

Cell lysates were prepared as described above and $\mathrm{Cx} 32-\mathrm{Myc} / \mathrm{His}$ was isolated with $\mathrm{Co} 2+-$ agarose resin. $\mathrm{Co} 2$ + purified Cx32 was analyzed by western blotting. 35-S-labeled Cx32 was detected by exposing the blots overnight to a storage phosphor and then imaging with a Storm Phosphorimager (GE Life Sciences). Then the blots were probed with antibodies against the Myc tag as a loading control. 35-S-Cx32 and Cx32-Myc/His bands were quantified using image-J and normalized; that is, 35-S-Cx32 values were obtained for each sample by dividing 35-S-Cx32 band intensity by Cx32-Myc/His band intensity.

\section{Cell surface biotinylation}

Biotinylation experiments were carried out $48 \mathrm{~h}$ post-transfection, following a $3 \mathrm{~h}$ treatment with TubA or DMSO. Confluent $60 \mathrm{~mm}$ plates of transfected cells were used for each experimental sample. Cell surface proteins were labeled with EZ-Link Sulfo-NHS-SS-Biotin $(0.5 \mathrm{mg} / \mathrm{ml}$; Thermo Scientific) for $30 \mathrm{~min}$ on ice. After biotinylation, cells were rinsed and blocked with PBS supplemented with $100 \mathrm{mM}$ Glycine. Samples were lysed immediately or chased for $1.5 \mathrm{~h}$ with complete medium in the presence of TubA or DMSO, as indicated.

Cells were harvested and lysed in PBS supplemented with $1 \%$ Triton-X 100 and protease inhibitors, as described for immunoprecipitation. Aliquots of total 
protein were obtained prior to isolation of biotinylated proteins. Biotinylated proteins were isolated by binding to neutravidin-agarose beads (Thermo Scientific) and then eluted with SDS-PAGE sample buffer and subjected to western blotting along with total protein samples. Total protein samples were diluted accordingly to permit detection of both the eluate and total fractions using the same blotting conditions. Biotinylated and total Cx32 was detected by probing with an antibody against Myc-tag.

\section{Electrophysiology}

Conductance measurements were made by pulsing from $\mathrm{Vj}=0$ to $+/-40 \mathrm{mV}$. After recording from cell pairs Cytoplasmic bridges were excluded by demonstrating the sensitivity of the recorded junctional conductance to application of bath solution containing octanol. Values for different pairing configurations were compared using the Kruskal-Wallis test with Dunn's multiple comparison post-test. For determination of steady-state junctional conductance-junctional voltage $(\mathrm{Gj}-\mathrm{Vj})$ relations, cells were held between each pulse at $\mathrm{Vj}=0$ for $22.5 \mathrm{~s}$, and cell 1 was pulsed in $20 \mathrm{mV}$ increments from -100 to $+100 \mathrm{mV}$ for $12.5 \mathrm{~s}$. Any resulting change in current in cell 2, the apposed cell, is attributable to junctional current. Currents are displayed with positive up for both cells; thus, a positive $\mathrm{Vj}$ step in cell 1 causes a downward deflection in cell 2. For WT and mutants with measurable conductance at $\mathrm{Vj}=0 \mathrm{mV}$, voltage pulses were preceded by a short $(\sim 200 \mathrm{mS})$ pulse to $-20 \mathrm{mV}$ for normalization. Data were collected as described. Steady-state $(t=\infty)$ conductances were determined by fitting each current trace to a sum of exponentials. Dividing the current at $\mathrm{t}=\infty$ by the applied voltage gives the steady-state junctional conductance.

For determination of Boltzmann parameters, steady-state plots were fit to the product of two Boltzmann distributions of the form:

$$
\begin{aligned}
\operatorname{Gss}(\mathrm{V})=\{ & \operatorname{Gmin}(+)+(\operatorname{Gmax}(+)-\mathrm{Gmin}(+)) / \\
& (1+\mathrm{e}[\mathrm{A}(+)(\mathrm{V}-\mathrm{V} 0(+))]\} * \\
& \{\operatorname{Gmin}(-)-\mathrm{Gmin}(-)) /(1+\mathrm{e}[\mathrm{A}(-)(\mathrm{V}-\mathrm{V} 0(-))])\}
\end{aligned}
$$

where Gss is the steady-state junctional conductance normalized to $\mathrm{Vj}=0$, Gmax is the maximal normalized conductance, and Gmin is the normalized residual conductance, which in macroscopic recordings is approached as the absolute value of $\mathrm{Vj}$ is increased, $\mathrm{V}_{0}$ is the voltage at which the conductance is $1 / 2$ of the difference between Gmin and Gmax and roughly corresponds to the voltage at which a single connexin hemichannel has an open probability of $50 \%$, and $\mathrm{A}$ is a parameter which reflects the slope of the $\mathrm{Gj}-\mathrm{Vj}$ plot and is a measure of voltage sensitivity. $\mathrm{A}=\mathrm{nq} / \mathrm{kT}$ where $\mathrm{n}$ is the effective gating charge and $\mathrm{q}, \mathrm{k}$ and $\mathrm{T}$ have their usual meanings. The $(+)$ and $(-)$ designations indicate that the parameters are fitted to the positive or negative limbs of the $\mathrm{Gj}-\mathrm{Vj}$ relation. The model makes two assumptions that may not always be met for connexin gating: 1.The gating process has two states, 1 where the energy difference between the states is proportional to the applied voltage, and 2: The steady state $\mathrm{Gj}-\mathrm{Vj}$ arises from the gating of two independent apposed hemichannels. Whether or not assumptions 1 and 2 are met, the parameters generated provide a useful basis for comparison among channels produced by various pairing configurations of mutant and WT connexins. Homotypic pairs of Cx32WT- IRES-EGFP served as a positive control and pairs of empty vector expressing cells served as negative controls for homotypic pairing of mutants. For heterotypic cell pair controls, an additional "heterotypic" pairing of Cx32WT-IRES-EGFP with Cx32WT-IRES- DSRed expressing cells was performed. Pipette solution: $145 \mathrm{mM} \mathrm{CsCl}, 5 \mathrm{mM}$ EGTA, $1.4 \mathrm{mM}$ $\mathrm{CaCl}$, $5.0 \mathrm{mM}$ HEPES pH 7.2; Bath solution: $150 \mathrm{mM}$ $\mathrm{NaCl}, 4 \mathrm{mM} \mathrm{KCl}, 1 \mathrm{mM} \mathrm{MgCl} 2,2 \mathrm{mM} \mathrm{CaCl} 2,5 \mathrm{mM}$ Dextrose, 2 mM Pyruvate, 5 mM HEPES; pH 7.4.

\section{Results \\ HDAC6 inhibition causes $\mathrm{C} \times 32$ protein accumulation}

Post-translational acetylation can regulate protein turnover [50-53]. Histone deacetylases (HDACs) form a functional class of cellular enzymes that remove acetyl groups from modified lysines of histones and other proteins. We chose inhibitors of HDACs as tools to investigate whether Cx32 is post-translationally acetylated and if this alters levels or stability of accumulated Cx32. Treatment of Cx32 transfected HeLa cells with a broad spectrum HDAC inhibitor, Trichostatin A (TSA), resulted in a 2.5 -fold accumulation of $\mathrm{Cx} 32$ protein relative to untreated transfected cells (Fig. 1a). Histone Deacetylase 6 (HDAC6) is a cytoplasmic protein $[54,55]$ with several known non-histone cytoplasmic substrates [56-58]. Unlike other HDACs inhibited by TSA, HDAC6 inhibition does not alter histone acetylation. We therefore hypothesized that specific inhibition of HDAC6 would also result in the accumulation of acetylated Cx32 protein, independent of transcriptional perturbations that can result from broad spectrum TSA HDAC inhibition.

Treatment of transfected cells with the HDAC6specific inhibitor, TubastatinA (TubA; Fig. 1b) increased the relative levels of $\mathrm{Cx} 32$ protein levels (3.7-fold \pm 0.35 SEM, $N=5$ independent experiments) compared to vehicle treated cells. To determine whether HDAC6 inhibition altered the half-life of Cx32, we performed 35-S pulse-chase experiments, comparing turnover of Cx32 in transfected cells treated with TubA to those treated with vehicle alone. 35-S labeled Cx32 detected by phosphorimaging was compared to total $\mathrm{Cx} 32$; Fig. 1c shows that half-life was increased by TubA treatment compared to 
untreated samples. To control for increased levels of Cx32 following TubA treatment, blots were normalized to total $\mathrm{Cx} 32$ for each treatment condition and reported as the percentage 35-S Cx32 remaining at $t=1.5 \mathrm{~h}$. HDAC6 inhibition approximately doubled the amount of 35-S-Cx32 remaining at $1.5 \mathrm{~h}$ (from $40 \%$ in vehicle treated controls to $79 \%$ in TubA treated samples; Fig. 1d.). These results suggest that increased accumulation of $\mathrm{Cx} 32$ in response to HDAC6 inhibition results from stabilization of Cx32 protein rather than increased $\mathrm{Cx} 32$ transcription.

To confirm TubA activity, relative levels of Cx32 acetylation were determined using anti-acetylated lysine antibody (AcK) to probe western blots of immunoprecipitated Cx32. This revealed increased acetylation of Cx32 in concert with increases $\mathrm{Cx} 32$ protein in response to TubA inhibition of HDAC6 (Fig. 1e).

We next asked whether stabilization of $\mathrm{Cx} 32$ in Cx32-transfected cells resulted from reduced turnover of cell-surface-localized Cx32 or increased presence in other subcellular compartments. Cell-surface biotinylation experiments were carried out to determine if acetylated Cx32 was accumulating preferentially at the cell surface. This was assessed by comparing the cell surface-labeled Cx32 in cells that had either been treated with TubA or DMSO immediately after labeling and after a1.5 h chase period.

Cx32-transfected cells were pre-treated with TubA or DMSO for three hours and subsequently labeled with Sulfo-NHS-SS-Biotin, a membrane impermeant biotin derivative, to tag cell surface proteins. Following cell-surface biotinylation, the cells were either lysed immediately $\left(\mathrm{T}_{0}\right)$ or incubated an additional $1.5 \mathrm{~h}\left(\mathrm{~T}_{1.5}\right)$ in the presence of TubA- or DMSO-containing medium to assess the total amount of biotinylated Cx32 from the cell surface labeled pool remaining at $\mathrm{T}_{1.5}$ following quenching. Biotinylated and total $\mathrm{Cx} 32$ were determined following western blot. Biotinylated Cx32 levels were normalized to total immunoprecipitated $\mathrm{Cx} 32-\mathrm{Myc}$ and expressed as the ratio biotinylated:total Cx32 (Fig. 2a). Vehicle-treated controls showed a higher ratio of biotinylated $\mathrm{Cx} 32$ to total $\mathrm{Cx} 32$ (2.0 $\pm 0.24 \mathrm{SEM}, N=3$ independent experiments) at $\mathrm{T}_{0}$, compared to TubA-treated cells $(0.76 \pm 0.09$ SEM, $N=3$ independent experiments) (Fig. 2b). Treatment with TubA resulted in elevated levels of biotinylated-Cx32 relative to total Cx32 at $1.5 \mathrm{~h}$ after cell-surface labeling; suggesting that inhibition of HDAC6 which increases relative levels of acetylated Cx32 also stabilizes the membraneassociated (biotinylated) pool of Cx32. At $1.5 \mathrm{~h}$ post-biotinylation, $82 \%( \pm 12 \%$ SEM,$N=3$ independent experiments) of biotinylated $\mathrm{Cx} 32$ relative to total $\mathrm{Cx} 32$ remained in TubA samples while only $48 \%( \pm 5.5 \%$ SEM, $N=3$ independent experiments) of biotinylated Cx32 remained in vehicle-treated samples (Fig. 2c); further supporting the conclusion that $\mathrm{Cx} 32$ levels are stabilized or enhanced by TubA inhibition of HDAC6 and that reduced acetylated-Cx32 at baseline in the absence of TubA (Fig. 1e) leads to loss of biotinylated Cx32 following quenching. Immunofluorescent staining and confocal imaging confirmed these results (Fig. 2d, Additional file 1: Figure S2, Additional file 2: Figure S3, Additional file 3: Figure $S 4$ and Additional file 4: Figure S5). Cx32 staining in both cytoplasmic and cell surface pools was visibly increased after $6 \mathrm{~h}$ of TubA treatment (Fig. 2d, Additional file 1: Figure S2, Additional file 2: Figure S3, Additional file 3: Figure S4 and Additional file 4: Figure S5). Taken together, these results suggest that inhibition of HDAC6 decreases degradation and stabilizes Cx32, leading to its accumulation in both cell surface and cytoplasmic cell compartments.

C-terminal lysines are implicated in HDAC6 inhibitor response Connexins contain three cytoplasmic domains (N-terminus, cytoplasmic loop, and C-terminus) that provide potential sites for regulation of protein turnover by posttranslational modification. Nine lysines were identified in the cytoplasmic domains of Cx32. To determine if these residues were targets for acetylation and enhanced accumulation of $\mathrm{Cx} 32$, point mutations for each cytoplasmic lysine were generated and tested for resistance to the effects of HDAC6 inhibition. Mutation of lysine to arginine $(\mathrm{K} \rightarrow \mathrm{R})$ conserves the positive charge from lysine, but blocks acetylation $[50,59]$. By contrast, lysine to glutamine mutations $(\mathrm{K} \rightarrow \mathrm{Q})$ are often mimetic of acetylation [59]. $K \rightarrow \mathrm{R}$ mutants in the cytoplasmic loop showed no differences compared to WT at baseline or following TubA (Fig. 3a, top), indicating the acetylation state of residues in this domain were not involved in mediating levels of Cx32 protein. Individual $\mathrm{K} \rightarrow \mathrm{R}$ mutation of $\mathrm{C}$-terminal lysines, however, reduced the TubA-stimulated accumulation of Cx32 protein, as compared to WT Cx32 (Fig. 3a bottom, 3B). To determine whether alteration of all five C-terminal lysines would further impact Cx32 accumulation, constructs in which all five C-terminal lysines were converted to arginine (5R) or glutamine (5Q) were tested for TubA induced accumulation of $\mathrm{Cx} 32$. Figure $3 \mathrm{~b}$ shows that $5 \mathrm{R}$ Cx32 is resistant to TubA treatment, whereas HDAC6 inhibition in 5Q Cx32 results in increased levels of Cx32.

To determine whether modification of several C-terminal lysines was necessary for the effect, constructs in which all five C-terminal lysines were converted to arginine $(5 R)$ or glutamine $(5 \mathrm{Q})$ and probed for changes in acetylation. The double $\mathrm{K} 231+\mathrm{K} 260 \rightarrow \mathrm{R}$ mutant failed to detectably alter levels of Cx32 acetylation (Additional file 5: Figure S1), supporting the modification of all five C-terminal lysines. Cx32 was immunoprecipitated from transfected cells and acetylated Cx32 was detected by western blotting. We found that $5 \mathrm{R}$ Cx32 was still acetylated, but that this acetylation did not increase in response 

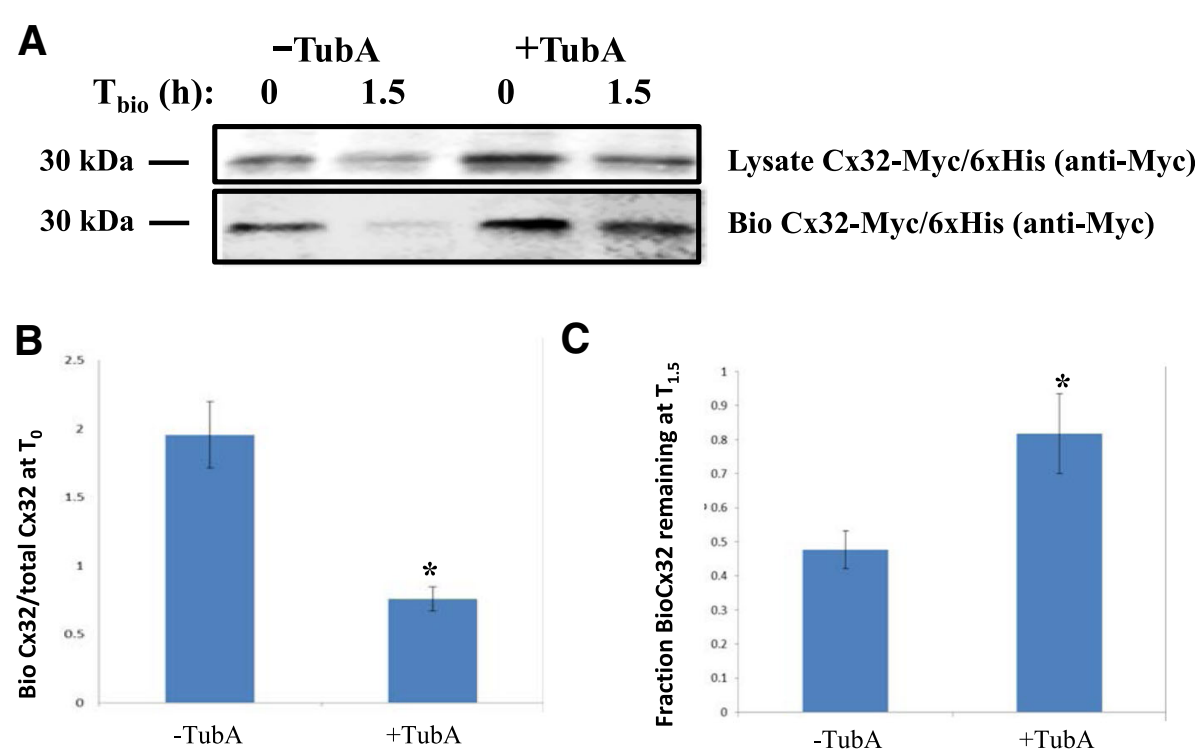

D

-TubA

+ TubA
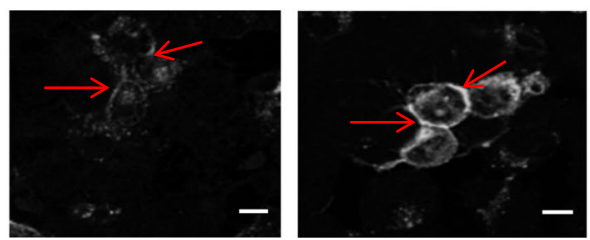

Fig. 2 HDAC6 inhibition results in the accumulation of both cytoplasmic and cell surface Cx32. a TubA treatment stabilizes Cx32 levels as determined by increases in levels of biotinylated Cx32 at $1.5 \mathrm{~h}$ after labeling. N2a cell were transfected with Cx32-Myc/6xHis and treated with TubA or vehicle for $3 \mathrm{~h}$ prior to biotinylation of cell surface proteins. Following cell surface biotinylation, cultures were harvested and processed for total lysate (top) and biotinylated Cx32-Myc/6xHis (bottom) by Western blot, as described in Methods. $\mathbf{b}$ Densitometric quantification of Western blots shows a significant reduction in biotinylated Cx32/total Cx32 at T0 in TubA-treated samples as compared to vehicle-treated cells. c A significant increase in biotinylated Cx32/total Cx32 remained at T1.5 compared to vehicle-treated ( $N=3$ independent experiments, Student's T-test $\left.{ }^{*} p<0.05\right)$. $\mathbf{d}$ Immunostaining and confocal microscopy cell surface labeling of Cx32 confirmed TubA treatment increases Cx32 accumulation in cell surface and cytoplasmic compartments (see also Additional file 5: Fig. S1). Images shown were obtained at 63X magnification and scale bars $=25 \mu \mathrm{m}$. Arrows indicate points of cell-cell contact

to TubA treatment $(0.86 \pm 0.15 \mathrm{SEM}, 5 \mathrm{R}$ vs WT; $N=4$ independent experiments) (Fig. 3c). This suggests that the observed increase in Cx32 acetylation and accumulation of $\mathrm{Cx} 32$ protein in response to HDAC6 inhibition was dependent upon $\mathrm{C}$-terminal lysines. The relative acetylation level of 5Q Cx32 was 3.86-fold lower than WT $(0.26 \pm 0.15 \mathrm{SEM}, 5 \mathrm{Q}$ vs WT; $N=4$ independent experiments) but increased in response to HDAC6 inhibition $(1.0 \pm 0.28 \mathrm{SEM}, 5 \mathrm{Q}$ vs WT; $N=4$ independent experiments) (Fig. 3c). This is agreement with our finding that accumulation of $5 \mathrm{Q} \mathrm{Cx} 32$ protein still occurred in response to HDAC6 inhibition (Fig. 3b). These results suggest that a subset of the C-terminal lysines could be acetylation sites, but other potential acetylation sites are available with HDAC6 inhibition under these experimental conditions.

To determine whether $5 \mathrm{R}$ and $5 \mathrm{Q}$ modification of $\mathrm{C}$-terminal lysines altered acetylation, cells transfected with $5 \mathrm{R}$ and $5 \mathrm{Q}$ constructs were treated with TubA and probed for changes in $\mathrm{Cx} 32$ acetylation compared to WT. The relative acetylation level of the 5Q Cx32 acetylation mimetic was 3.86 -fold lower than WT $(0.26$ \pm 0.15 SEM, 5Q vs WT; $N=4$ independent experiments) but increased in response to HDAC6 inhibition $(1.0 \pm 0.28$ SEM, 5Q vs WT; $N=4$ independent experiments) (Fig. 3c) in agreement with our finding that accumulation of $5 \mathrm{Q}$ Cx32 protein occurred in response to HDAC6 inhibition (Fig. 3b). The 5R Cx32 block mutant, however, was also acetylated, but this acetylation did not respond to HDAC6 inhibition with TubA $(0.86 \pm 0.15$ SEM, 5R vs WT; $N=4$ independent experiments) (Fig. 3c); suggesting that, under the experimental conditions described, other acetylation sites may become available with inhibition of HDAC6. Taken together, these results support the involvement of the C-terminal residues in the observed increase in $\mathrm{Cx} 32$ acetylation and accumulation of $\mathrm{Cx} 32$ protein following HDAC6 inhibition. 


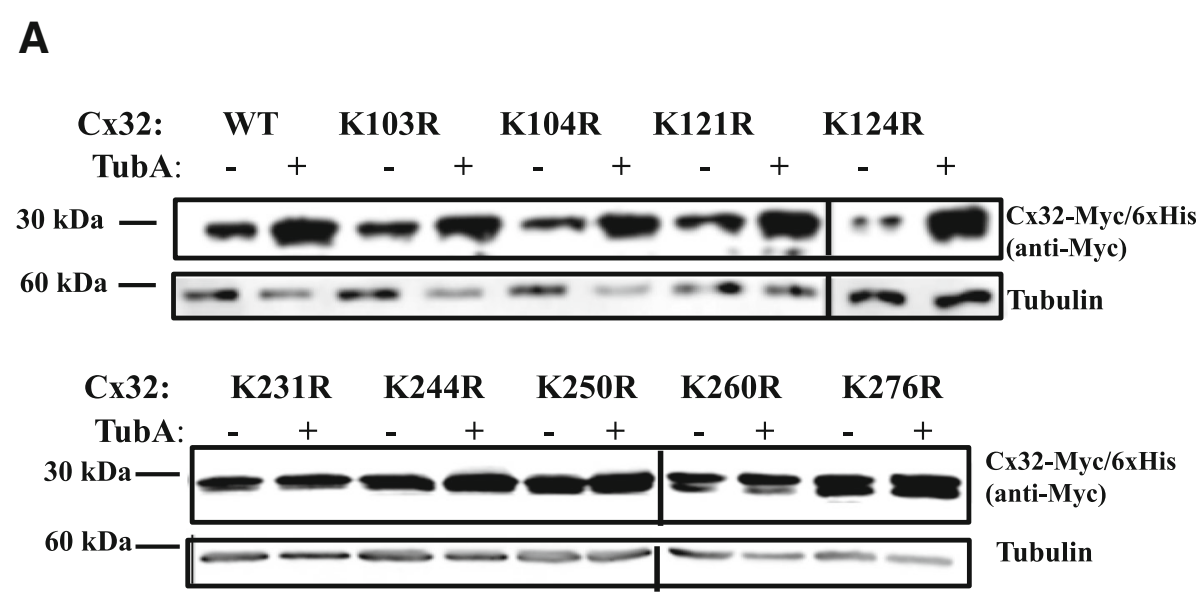

$\mathbf{B}$

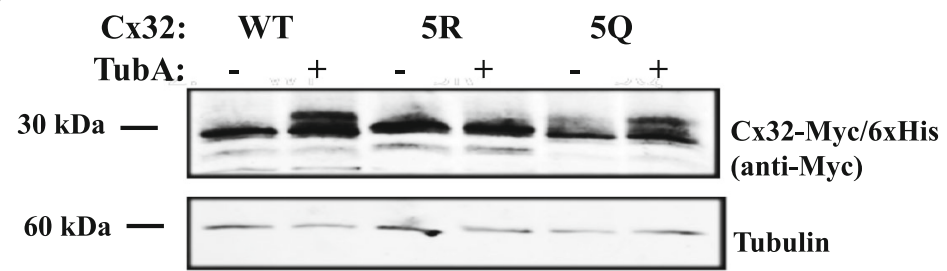

C

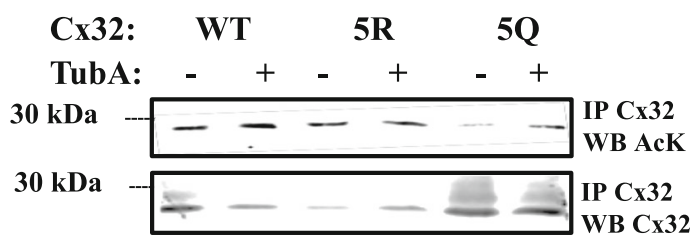

Fig. 3 C-terminal lysines are required for HDAC6 inhibitor-induced accumulation of Cx32. a Mutation of C-terminal (bottom), but not cytoplasmic loop (top), lysines prevented Cx32 accumulation in response to TubA treatment. N2a cells transfected with either Cx32-Myc/6xHis or site-specific $\mathrm{C} \times 32-\mathrm{Myc} / 6 \mathrm{xH}$ His $\mathrm{K} \rightarrow \mathrm{R}$ acetylation-deficient mutants were treated with DMSO or TubA and processed for Western blot. Blots were probed for Myc-tag to detect Cx32, with beta-tubulin as a loading control. (Note that vertical lines between samples in figure indicate use of sister blots, run simultaneously.) (b) N2a cells were transfected with either Cx32-Myc/6xHis (WT), acetylation-deficient multi-site lysine to arginine mutant of all five cytoplasmic C-terminal lysines (5R), or acetylation-mimetic multi-site lysine to glutamine mutant of the five C-terminal lysines (5Q). WT, 5R, 5Q expressing cultures were treated with TubA or vehicle and assessed for Cx32 expression as in (a). c WT, 5R, 5Q expressing cultures were treated with TubA or vehicle and assessed for acetylation with anti-AcK. Cultures were immunoprecipitated with affinity purified rabbit-anti-Cx32 (E. Hertzberg) and probed with mouse monoclonal anti-CX32 (7C6.7C; E. Hertzberg) or anti-AcK. Basal levels of acetylation were lower, as predicted, in untreated 5R and increased in 5Q relative to total Cx32. Treatment with TubA increased WT and $5 \mathrm{Q}$ acetylation, while $5 \mathrm{R}$ levels remained largely unchanged

\section{C-terminal lysines regulate Cx32 ubiquitination and turnover} Ubiquitination of lysines impacts protein turnover and can be regulated by lysine acetylation [60]. We hypothesized that hyper-acetylation of putative acetylation sites could reduce the availability of Cx32 ubiquitination sites, thereby reducing turnover of the protein. Levels of ubiquitination in the 5Q Cx32 mimetic was significantly lower relative to WT $(15 \%+/-2 \%$ SEM, $N=3$ independent experiments) (Figs. 4a, b). Ubiquitination of 5R Cx32 block was reduced to $47 \%(+/-15 \%$ SEM, $N=3$ independent experiments) of the WT level, consistent with observed baseline acetylation levels (Fig. 4a, b). Given that a poly-ubiquitinated and multiple mono-ubiquitinated protein present similarly by SDS
PAGE and Western blot, the possibility of a reduction in poly-ubiquination of $5 R$ must be considered along with decreases in mono-ubiquination. 35-S pulse-chase experiments showed that replacement of C-terminal lysines with glutamine $(5 \mathrm{Q})$, in order to mimic constitutive acetylation, slowed down Cx32 by turnover to an even greater extent than the $5 \mathrm{R}$ acetylation block mutation (Fig. 5a, b.), despite the reduction in turnover with $5 \mathrm{R}$ compared to WT (Fig. $5 \mathrm{a}, \mathrm{b})$. Taken together, these results confirm our initial observations with HDAC6 inhibition of WT Cx32 and provide further support for that modulation of C-terminal lysines, either by acetylation or ubiquitination, modulates Cx32 protein. 

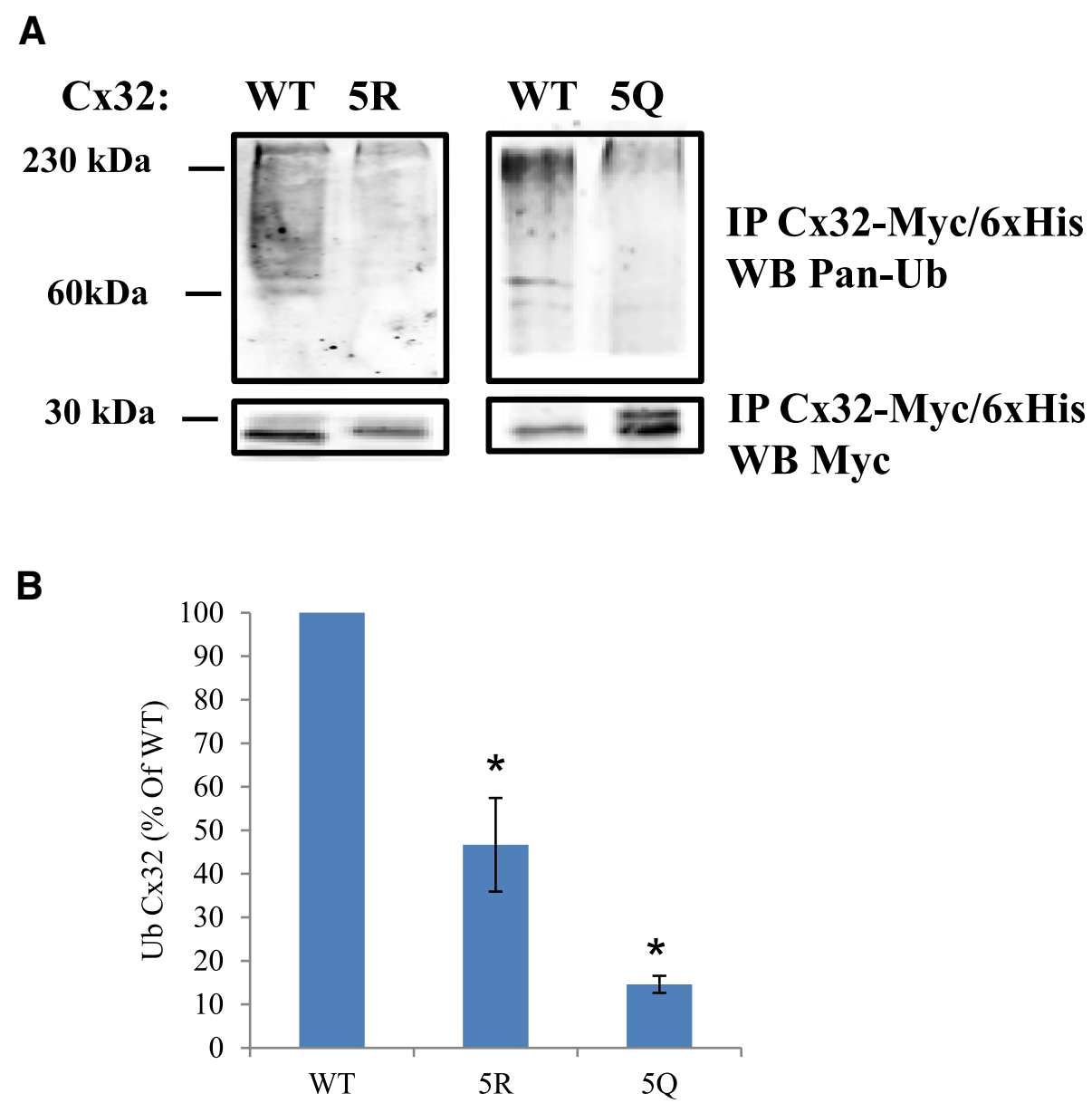

Fig. 4 C-terminal lysines modulate $C \times 32$ ubiquitination. a Ubiquitination levels of $5 R$, and $5 \mathrm{Q} C \times 32$, relative to $W T$, was assessed by probing Western blots of $\mathrm{Co} 2+$ affinity-purified $\mathrm{Cx} 32-\mathrm{Myc} / 6 \times \mathrm{H}$ is with antibodies against pan-ubiquitin and Myc-tag. Note that monoubiquitin has a molecular mass of $8.5 \mathrm{kDa}$ and thus the bands shown here could represent polyubiquitinated and multi-mono-ubiquitinated $\mathrm{Cx} 32$. $\mathbf{b}$ Densitometric quantification of Ub-Cx32 as a percentage of WT Ub-Cx32 is shown here. Relative levels of Ub-Cx32 were $47 \%$ and $15 \%$ for $5 R$ and $5 \mathrm{Q}$, respectively, versus WT ( $N=3$ experiments, Student's T-test: $\left.{ }^{*} p<0.05\right)$

\section{C-terminal lysines are dispensable for GJ function}

To determine if the $5 \mathrm{R}$ and $5 \mathrm{Q}$ mutants altered formation of functional Cx32 GJ, we performed dual whole cell recordings to assess trans-junctional conductance and voltage gating. Dual whole cell recordings of trans-junctional conductance indicated that $5 \mathrm{R}$ and $5 \mathrm{Q} \mathrm{Cx} 32$ formed functional GJ (Fig. 6a, b). Both Cx32 mutants generated trans-junctional voltages that were comparable to WT Cx32, indicating that cells expressing all three constructs were well coupled. We also evaluated the relationship between applied voltage and trans-junctional conductance to determine if the voltage gating of the either mutant differed from that of WT Cx32. The voltage gating of 5R and $5 \mathrm{Q}$ resembled WT $\mathrm{Cx} 32$, indicating that the mutations did not alter the structure of cytoplasmic motifs involved in voltage gating (Fig. 6c). This provided further evidence that neither the $\mathrm{C}$-terminal lysines of $\mathrm{Cx} 32$, nor their post-translational modification, are required for normal
GJ function. This is not surprising considering that the truncation of Cx32 at R220, has only a small effect on the steady state conductance- voltage relation.

\section{Cx32 acetylation regulates cellular proliferation}

Cytoplasmic domains of connexins have been implicated in a variety of physiological processes, such as the regulation of cellular proliferation, independent of their role in cell-cell communication [44, 61-63]. We hypothesized that acetylation of $\mathrm{Cx} 32$ could impact its role as a regulator of cellular proliferation. BrdU incorporation assays compared the fraction of proliferating cells found in cultures expressing WT, 5R, and 5Q Cx32. Expression of 5R Cx32 significantly reduced BrdU incorporation and immunolabeling (Fig. 7a, c) compared to WT and 5Q Cx32. This result suggests that blockade of $\mathrm{Cx} 32$ C-terminal acetylation can act as a modulator of channel-independent cellular processes, including cellular 
A

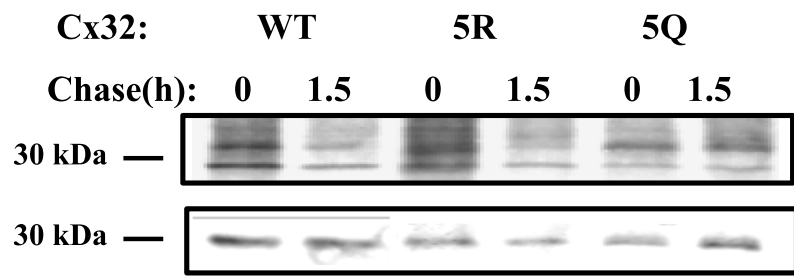

\title{
35-S Cx32-Myc/6xHis
}

\author{
WB: Cx32-Myc
}

B

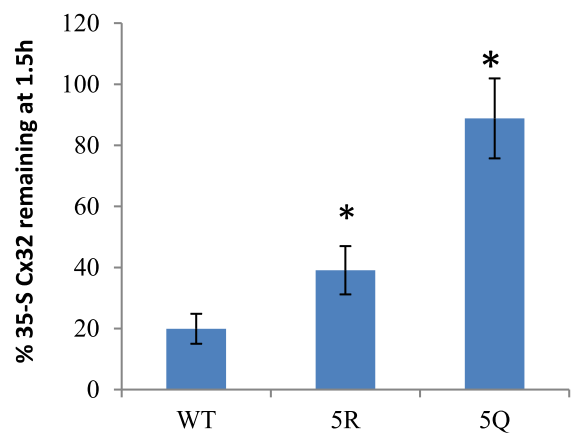

Fig. 5 C-terminal lysines modulate Cx32 turnover. a Cells expressing Myc/6xHis tagged WTCx32, 5RCX32, or 5QCx32 were pulsed with 35-S-Met/Cys for $5 \mathrm{~min}$ and lysed (0) or chased $1.5 \mathrm{~h}$ in complete medium (1.5). Cx32-Myc/His was isolated by affinity purification and processed for Western blotting. 35S-Met/Cys incorporation into newly synthesized Cx32-Myc/His was detected by phosphorimaging and the blots were subsequently probed with anti-Myc antibody to detect Cx32-Myc/His. b Densitometric quantification of 35-S Cx32 remaining after 1.5 h. 35-S was quantified and normalized to total Cx32-Myc amount ( ${ }^{*} p<0.05$, Student's T-test, $N=3$ )

proliferation. To determine whether expression of WT, $5 \mathrm{R}$, or $5 \mathrm{Q}$ Cx32 interfered with $\mathrm{N} 2 \mathrm{a}$ cell survival, the percentage of Cx32 expressing cells versus total cells in each group was determined. We detected no difference between the percentage of cells expressing either mutant versus WT (Fig. 7b, c), suggesting that the reduction in BrdU incorporation observed in the $5 \mathrm{R}$ group was likely due to decreased proliferation rate rather than to toxicity of the mutant protein.

\section{Discussion}

The data presented here address the role of C-terminal lysines and their post-translational modifications as regulators of Cx32 function. Our results demonstrate that acetylation of C-terminal lysines modulates levels and turnover of $\mathrm{Cx} 32$ protein in the cell. Changes in acetylation of these C-terminal lysines, in turn, alters ubiquitination of $\mathrm{Cx} 32$, such that levels of ubiquitination respond to occupancy or modification of these identified acetylation sites. Acetylation reduced turnover and increased accumulation of Cx32 protein throughout the cell. The acetylation state of C-terminal lysines did not affect functional GJ channel activity.

We utilized deacetylase inhibitors to promote the accumulation of acetylated Cx32 and determined that HDAC6 a regulator of $\mathrm{Cx} 32$ acetylation. Specific inhibition of HDAC6 stabilized Cx32 protein, causing it to accumulate throughout the cell, while increasing its acetylation and decreasing its ubiquitination. These results recapitulated our initial results with the broad type I and II deacetylase inhibitor, TSA. Our analysis of cytoplasmic lysine mutants of $\mathrm{Cx} 32$ revealed that $\mathrm{C}$-terminal lysines are involved in the Cx32 accumulation which results from HDAC6 inhibition. Previous studies have shown that $\mathrm{C}$-terminal truncation mutations of $\mathrm{Cx} 32$ retain the capacity to form functional GJ, with a resultant level of cell-cell coupling that is inversely proportional to the number of amino acids that were truncated $[64,65]$. Furthermore, much of the truncated Cx32 accumulates in the cytoplasm, implicating the $\mathrm{C}$ - terminus in the regulation of GJ assembly and/or disassembly [66]. We found that the C-terminal $\mathrm{K} \rightarrow \mathrm{R}$ and $\mathrm{K} \rightarrow \mathrm{Q}$ mutations did not prevent $\mathrm{Cx} 32$ from reaching the cell surface (Additional file 1: Figure S2 and Additional file 2: Figure S3) but may alter the levels of plasma membrane Cx32 maintained over time. The results presented provide further support for a model of GJ assembly that is regulated by the $\mathrm{C}$-termini of connexins. Specifically, post-translational modifications of C-terminal lysines modulate the amount of $\mathrm{Cx} 32$ maintained at the cell surface. This cell surface pool of Cx32 may be incorporated into GJ or may exist as hemichannels, either of which could regulate downstream physiological processes.

Our interpretation of the single residue $K \rightarrow R$ mutations shown in Fig. 3a. is limited by the possibility that 
A

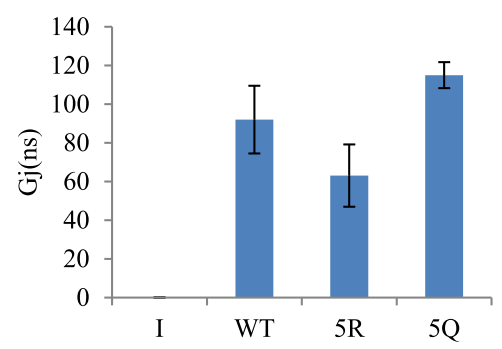

C

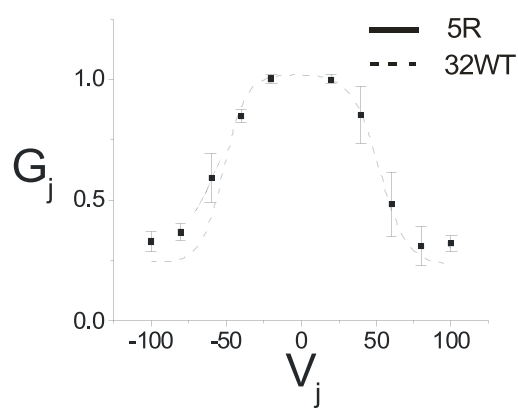

B

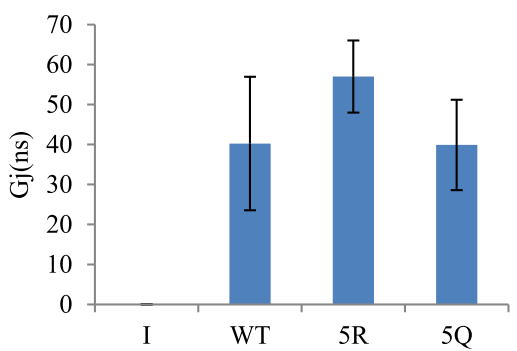

$\mathrm{C} \times 325 \mathrm{Q}$

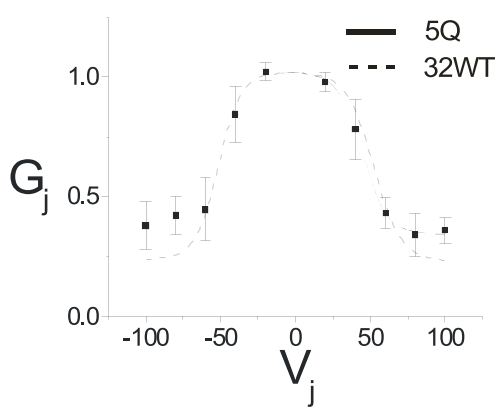

Fig. 6 C-terminal lysine mutants form functional gap junctions. a Dual whole-cell recordings showed no significant differences in junctional conductance $(\mathrm{Gj})$ between WT, 5R, or $5 \mathrm{Q}$ cell pairs. Mean Junctional conductances for pIRES2EGFP (I), WT, 5R, and 5Q Cx32 are plotted. b Cells in experiments plotted here were transfected with 3-fold more DNA than in A; no influence on Gj activity is observed. c Representative average normalized Gj-Vj relations with 5R (left) and 5Q (right) are compared with Cx32WT channels. The average normalized instantaneous (open triangles) and steady-state (filled squares) junctional conductance (Gj) at each Vj were calculated from current traces and fit as described in the Materials and Methods. Solid lines represent fits to Cx32-5R or Cx32-5Q; broken lines represent fits to data for Cx32WT homotypic cell-cell channels

modifications at a given residue result in alterations of accessibility to or post translational modifications of other residues, thereby enhancing or masking the effect of a given mutation on the accumulation of Cx32 in response to HDAC6 inhibition. Additionally, it is possible that HDAC6 inhibition causes Cx32 accumulation through mechanisms that are both directly dependent upon Cx32 acetylation and dependent upon the hyperacetylation of other HDAC6 substrates. However, since we have shown that mutations that mimic constitutive acetylation of $\mathrm{C}$ terminal lysines $(\mathrm{K} \rightarrow \mathrm{Q})$ recapitulate the impact of HDAC6 inhibition on Cx32 turnover, ubiquitination and plasma membrane localization, the accumulation of Cx32 that is observed after HDAC6 inhibition can be largely attributed to direct modulation of post-translational modifications of $\mathrm{Cx} 32$.

Expression levels of 5R Cx32 acetylation were roughly equivalent to WT but did not increase in response to HDAC6 inhibition. This suggests that the five C-terminal lysines are acetylated in response to HDAC6 inhibition, and that other acetylated Cx32 lysine targets remain in the full-length protein. A possible source of this residual acetylation in the $5 \mathrm{R}$ mutant may be the result of additional or spurious acetylation of other lysines when normal sites are unavailable. 5Q Cx32 acetylation is visibly decreased as compared to $5 \mathrm{R}$ and WT, suggesting that the $K \rightarrow Q$ mutation specifically succeeds in eliminating acetylation sites. Total acetylation levels of $5 \mathrm{Q}$ Cx32 increase after HDAC6 inhibition, with no concomitant increase in $\mathrm{Cx} 32$ protein accumulation.

We detected Cx32 as a doublet by Western blotting when cells expressing WT or TubA sensitive mutants were treated with TubA or when putative acetylation sites were mutated to glutamine (5Q) to mimic constitutive acetylation. It is possible that the higher molecular mass band in these samples is an additional post translationally modified form of Cx32. A previous study identified S240 as a phosphorylation site and C280/283 as palmitoylation sites [45]. Given the proximity of those residues to the putative acetylation sites identified here, it is conceivable that those or other post translational modifications could be positively regulated by acetylation.

Acetylation of Cx32 also appears to alter proliferation of transfected N2a cells. Specifically, expression of 5R, which blocks acetylation and conserves the charge properties of the mutated lysines, reduced proliferation, while proliferation in cells expressing the acetylation mimetic, $5 \mathrm{Q}$, did not differ significantly from those expressing 


\section{A}

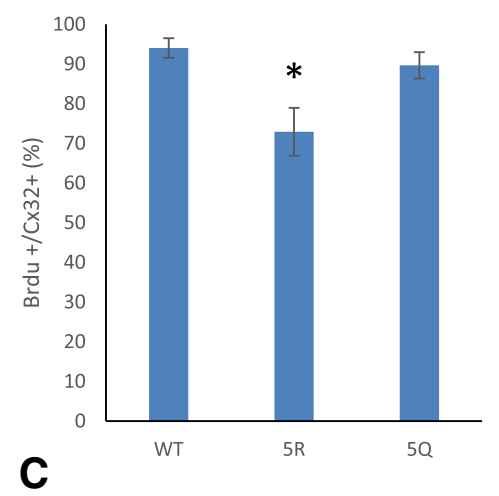

B

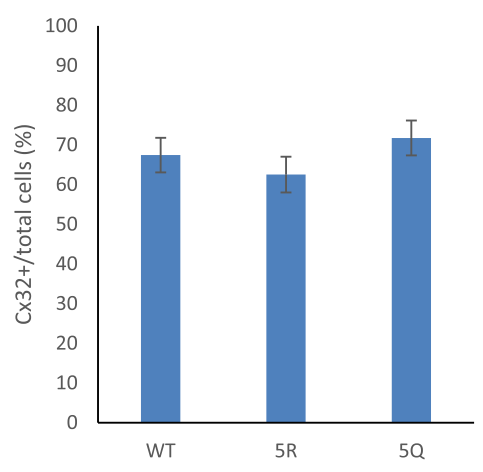

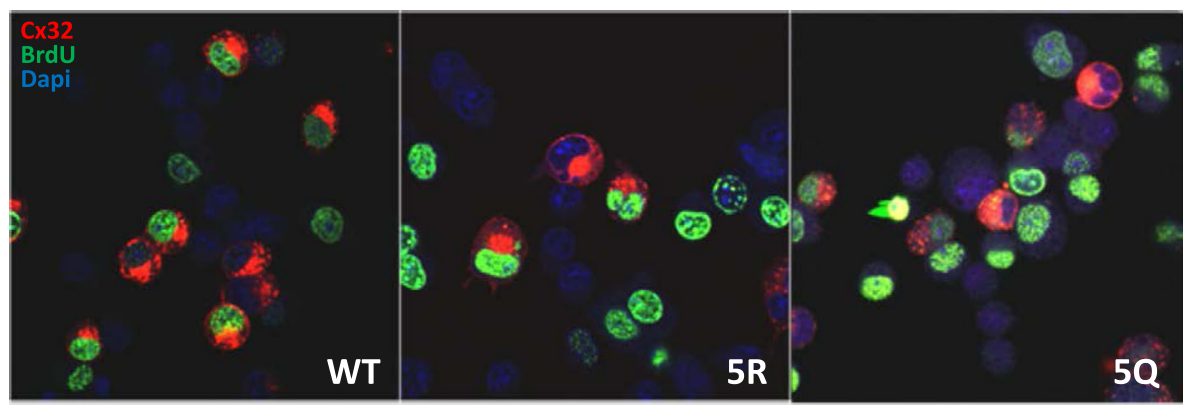

Fig. 7 Cellular proliferation is regulated by Cx32 acetylation. BrdU incorporation by N2a cells expressing the pCx32-IRESEGFP WT, 5R, or 5Q constructs were quantified by immunofluorescent staining for $\mathrm{C} \times 32$ and BrdU, as described in methods. Following overnight incubation with medium containing BrdU, cells were fixed, labeled and scored for Cx32 expression and BrdU incorporation. The percentage of BrdU-positive and Cx32 co-expressing cells were normalized to the total number of Cx32-expressing cells for each construct. a The percentage of BrdU positive cells in $5 R$ samples were significantly reduced compared to WT $\left(^{*} p<0.0026\right)$. $\mathbf{b}$ No differences in the percentage of Cx32 positive cells per total DAPI positive nuclei (cell number) were noted. For each construct, three to four fields were imaged and quantified for each replicate coverslip per experiment using the MultiWavelength Cell Scoring app in Metamorph, as described in the Methods. ( $N=3$ experiments for each construct). c Representative images of BrdU incorporation by N2a cells expressing the pCx32-IRESEGFP WT, 5R, or 5Q constructs, labeled and processed as described above

WT. Expression of Cx32 can act as either a positive or a negative regulator of proliferation depending upon the cell type and physiological context [6]. Our results suggest that acetylation of Cx32 is a modulator of proliferation and that the loss of acetylation sites suppresses proliferation of N2a cells. Thus, the acetylation state of C-terminal lysines in Cx32 has a role in regulating proliferation, an essential cell function. This modulation of proliferation rate may be occurring through acetylation specific protein-protein interactions rather than the general presence of lysines at the positions that we analyzed. Simply substituting a lysine with an amino acid that could not be otherwise modified (Cx32 5Q versus Cx32 5R), for example by ubiquitination, was not sufficient to suppress the proliferation modulating function of Cx32. Additionally, stabilization of Cx32 alone was not sufficient to modulate cellular proliferation because both $5 \mathrm{Q}$ and $5 \mathrm{R}$ Cx32 were more stable than WT and accumulated in the cell, but only Cx32 5R suppressed proliferation.

A recent study has identified several di-leucine-like motifs in the $\mathrm{C}$ terminus of $\mathrm{Cx} 32$ that regulate its endocytosis [67]. Two of our putative acetylation sites, $\mathrm{K} 250$ and K260, fall within two of these dileucine like motifs. Mutations within these motifs (L251A + L252A and L263A + R264A) increase GJ surface area and slow down turnover of $\mathrm{Cx} 32$ from the cell surface, due to reduced endocytosis. It is possible that cross talk between post translational modifications such as acetylation and ubiquitination involve these regulatory motifs.

Connexins are paradigmatic of a large cohort of proteins that are regulated by interactions with binding partners, which cause a particular sequence to change from an intrinsically disordered state into a functional secondary structure $[68,69]$. For example, Stauch, et al. [69] report that binding of calmodulin $(\mathrm{CaM})$ to the Cx32 C-terminus orders and stabilizes it into an alpha-helix. Chemical gating of Cx32 GJ occurs in the presence of high concentrations of $\mathrm{Ca} 2+$, which may lead to CaM activation and structural change in the C-terminus of Cx32 [43, 70]. Inhibition of CaM binding or truncation of $\mathrm{CaM}$ binding sites resulted in cytoplasmic accumulation of $\mathrm{Cx} 32$, further highlighting the 
regulatory role of interactions between $\mathrm{Cx} 32 \mathrm{C}$ - terminus and binding partners [66]. Other physiologically significant roles, such as the regulation of GJ assembly [64], cellular proliferation [44] and $\mathrm{CO}_{2}$ mediated GJ gating [71] have also been identified for the C-terminus of Cx32. However, little is known about the molecular mechanisms that control these functions, potentially through fine-tuning interactions between Cx32 and its binding partners. The results presented here suggest that the presence or absence of an acetyl group or the charged lysine in the C- terminus of $\mathrm{Cx} 32$ could be a modulator of interactions with binding partners, leading to alterations in Cx32 protein stability and physiological function.

\section{Conclusions}

We have identified acetylation sites in the five lysines in the C-terminus of Cx32. Mutational analysis to acetylation deficient- or mimetic-residues demonstrates that these lysines play a potential role in regulating Cx32 ubiquitination, stability, and turnover. Inhibition of HDAC6 leads to accumulation of acetylated $\mathrm{C} x 32$ protein, providing further evidence for HDAC6 modulation of Cx32 acetylation levels. Further analysis of the $\mathrm{C}$-terminal mutants demonstrated that these critical lysine residues do not alter Cx32-mediated gap junction conductances, rather the acetylation state of these $\mathrm{C}$-terminal lysines appears to regulate $\mathrm{Cx} 32$ protein turnover and to impact channel-independent functions, including cellular proliferation. These results highlight the role of lysines in the C-terminal tail of Cx32 in the fine-tuning of Cx32 stability and channel-independent functions.

\section{Additional files}

Additional file 1: Figure S2. C-terminal lysines influence Cx32 localization and HDACi response. (A.) Cell surface biotinylation was performed in order to confirm the presence of WT, 5R, and 5Q Cx32 at the cell surface. Biotinylated and total Cx32 were detected by probing Western blots with an antibody against the Myc-tag. (B. and $\mathbf{C}$.) N2A cells were transfected with WT, $5 \mathrm{R}$, or $5 \mathrm{Q}$ and treated with TubA or vehicle (C), as described in methods. The amount of $\mathrm{C} \times 32$ at points of cellcell contact was measured by quantifying the fluorescence intensity of Cx32 antibody staining $48 \mathrm{~h}$ after transfection. (B.) Confocal images of Cx32 immunostaining, scale bars are $25 \mu \mathrm{m}$ and arrows indicate points of cell-cell contact.(C.) Anti-Cx32 fluorescence intensity at points of cellcell contact was measured. Average fluorescence intensities at cell-cell contacts for each set of images is plotted. ( $n=15$ cell pairs for each group; ${ }^{*} p<0.05$ compared to WT-TubA, Student's T-test). (PDF $147 \mathrm{~kb}$ )

Additional file 2: Figure S3. C-terminal lysines influence Cx32 localization and HDACi response. Additional representative images of WT Cx32 expressing N2a cells (+/- TubA) shown in Figure S2. (PDF 244 kb)

Additional file 3: Figure S4. C-terminal lysines influence Cx32 localization and $\mathrm{HDACi}$ response. Additional representative images of $5 R$ Cx32 expressing N2a cells (+/- TubA) shown in Figure S2. (PDF 317 kb)

Additional file 4: Figure S5. C-terminal lysines influence $C \times 32$ localization and $\mathrm{HDACi}$ response. Additional representative images of $5 \mathrm{Q}$ Cx32 expressing N2a cells (+/- TubA) shown in Figure S2. (PDF 269 kb)
Additional file 5: Figure S1. Mutation of K231 and K260 does not eliminate acetylation. N2a cells were transfected with pIRESeGFP-Cx32 WT or K231+260R for 48 hours as described in methods section, then treated overnight with $20 \mu \mathrm{M}$ Tubastatin. Cx32 was immunoprecipitated and blotted with indicated antibodies. (PDF $9 \mathrm{~kb}$ )

\section{Abbreviations}

BrdU: Bromodeoxyuridine; Cx32: Connexin32; HDAC6: Histone deacetylase 6; N2a: Neuro2-A; TSA: TrichostatinA; TubA: Tubstatin A

\section{Funding}

Funding for the work presented was provided by NIH-1R01GM088660 awarded to J.C.B.

\section{Availability of data and materials}

The data used and/or analyzed during the current study are available from the corresponding author on reasonable request.

\section{Authors' contributions}

SRA was responsible for experimental design, implementation, data analysis, and manuscript preparation. SRA also performed biochemical, protein turnover, Western blot, image acquisition, and immunolabeling experiments. ELH provided pEGFPIRES2 vector and Cx32 antibodies and assisted with project and experimental design. MMF assisted with manuscript preparation, data analysis, and performed BrdU proliferation experiments. CKA advised on experimental design and performed electrophysiology experiments. JCB provided support for experimental design, implementation, and manuscript preparation. All authors read and approved the final manuscript.

Ethics approval and consent to participate

Not applicable

\section{Consent for publication}

Not applicable

\section{Competing interests}

The authors declare that they have no competing interests.

\section{Publisher's Note}

Springer Nature remains neutral with regard to jurisdictional claims in published maps and institutional affiliations.

\section{Author details}

${ }^{1}$ Department of Molecular Genetics \& Microbiology, Stony Brook University, Stony Brook, NY 11794, USA. ²Department of Neurology \& Rehabilitation, University of Illinois at Chicago, Chicago, IL 60612, USA. ${ }^{3}$ Department of Cell \& Molecular Biology, Columbia University, New York, NY 10032, USA.

Received: 13 February 2018 Accepted: 17 September 2018

Published online: 29 September 2018

\section{References}

1. Warner AE, Guthrie SC, Gilula NB. Antibodies to gap-junctional protein selectively disrupt junctional communication in the early amphibian embryo. Nature. 1984;311(5982):127-31

2. Abrams CK, Rash JE: Connexins in the nervous system. In: Connexins: A Guide. Edited by Harris AL, Locke D: Humana Press; 2009: 323-358.

3. Kar R, Batra N, Riquelme MA, Jiang JX: Biological role of connexin intercellular channels and hemichannels. Arch Biochem Biophys 2012(0).

4. Kumar NM, Gilula NB. The gap junction communication channel. Cell. 1996; 84(3):381-8

5. Dyce PW, Norris RP, Lampe PD, Kidder GM. Phosphorylation of serine residues in the C-terminal cytoplasmic tail of connexin43 regulates proliferation of ovarian granulosa cells. J Membr Biol. 2012;245(5-6):291-301.

6. Freidin M, Asche S, Bargiello TA, Bennett MV, Abrams CK. Connexin 32 increases the proliferative response of Schwann cells to neuregulin-1 (Nrg1). Proc Natl Acad Sci U S A. 2009;106(9):3567-72.

7. Shi Q, Gu S, Yu XS, White TW, Banks EA, Jiang JX. Connexin controls cellcycle exit and cell differentiation by directly promoting cytosolic localization and degradation of E3 ligase Skp2. Dev Cell. 2015;35(4):483-96. 
8. Bejarano E, Yuste A, Patel B, Stout RF Jr, Spray DC, Cuervo AM. Connexins modulate autophagosome biogenesis. Nat Cell Biol. 2014;16:401.

9. Polusani SR, Kalmykov EA, Chandrasekhar A, Zucker SN, Nicholson BJ. Cell coupling mediated by connexin 26 selectively contributes to reduced adhesivity and increased migration. J Cell Sci. 2016;129(23):4399-410.

10. Yang J, Liu B, Wang Q, Yuan D, Hong X, Yang Y, Tao L. Connexin 32 and its derived homotypic gap junctional intercellular communication inhibit the migration and invasion of transfected HeLa cells via enhancement of intercellular adhesion. Mol Med Rep. 2011;4(5):971-9.

11. Saidi Brikci-Nigassa A, Clement MJ, Ha-Duong T, Adjadj E, Ziani L, Pastre D, Curmi PA, Savarin P. Phosphorylation controls the interaction of the connexin43 C-terminal domain with tubulin and microtubules. Biochemistry. 2012;51(21):4331-42

12. Kausalya PJ, Reichert M, Hunziker W. Connexin45 directly binds to ZO-1 and localizes to the tight junction region in epithelial MDCK cells. FEBS Lett. 2001;505(1):92-6.

13. Toyofuku T, Yabuki M, Otsu K, Kuzuya T, Hori M, Tada M. Direct association of the gap junction protein connexin-43 with ZO-1 in cardiac myocytes. J Biol Chem. 1998;273(21):12725-31.

14. Hunter AW, Gourdie RG. The second PDZ domain of zonula occludens-1 is dispensable for targeting to connexin 43 gap junctions. Cell Commun Adhes. 2008;15(1):55-63.

15. Bargiello TA, Tang Q, Oh S, Kwon T. Voltage-dependent conformational changes in connexin channels. Biochim Biophys Acta. 2012;1818(8):1807-22.

16. Engelhardt K, Schmidt M, Tenbusch M, Dermietzel R. Effects on channel properties and induction of cell death induced by c-terminal truncations of pannexin1 depend on domain length. J Membr Biol. 2015;248(2):285-94.

17. Peracchia C, Wang XG, Peracchia LL. Chemical gating of gap junction channels. Methods San Diego, Calif. 2000;20(2):188-95.

18. Wang XG, Peracchia C. Chemical gating of heteromeric and heterotypic gap junction channels. J Membr Biol. 1998;162(2):169-76.

19. DeRosa AM, Mui $R$, Srinivas M, White TW. Functional characterization of a naturally occurring Cx50 truncation. Invest Ophthalmol Vis Sci. 2006;47(10):4474-81.

20. Kretz M, Maass K, Willecke K. Expression and function of connexins in the epidermis, analyzed with transgenic mouse mutants. Eur J Cell Biol. 2004; 83(11-12):647-54.

21. Maass K, Shibayama J, Chase SE, Willecke K, Delmar M. C-terminal truncation of connexin43 changes number, size, and localization of cardiac gap junction plaques. Circ Res. 2007;101(12):1283-91.

22. Zhang YW, Kaneda M, Morita I. The gap junction-independent tumorsuppressing effect of connexin 43. J Biol Chem. 2003;278(45):44852-6.

23. Hatakeyama T, Dai P, Harada Y, Hino H, Tsukahara F, Maru Y, Otsuji E, Takamatsu T. Connexin43 functions as a novel interacting partner of heat shock cognate protein 70. Sci Rep. 2013;3:2719.

24. Kardami E, Dang X, lacobas DA, Nickel BE, Jeyaraman M, Srisakuldee W, Makazan J, Tanguy S, Spray DC. The role of connexins in controlling cell growth and gene expression. Prog Biophys Mol Biol. 2007;94(1-2):245-64.

25. Mitra SS, Xu J, Nicholson BJ. Coregulation of multiple signaling mechanisms in pp60v-Src-induced closure of Cx43 gap junction channels. J Membr Biol. 2012;245(8):495-506

26. Dunn CA, Lampe PD. Injury-triggered Akt phosphorylation of Cx43: a ZO-1driven molecular switch that regulates gap junction size. J Cell Sci. 2014; 127(Pt 2):455-64.

27. Solan JL, Lampe PD. Specific Cx43 phosphorylation events regulate gap junction turnover in vivo. FEBS Lett. 2014:588(8):1423-9.

28. Johnson KE, Mitra S, Katoch P, Kelsey LS, Johnson KR, Mehta PP. Phosphorylation on Ser-279 and Ser-282 of connexin43 regulates endocytosis and gap junction assembly in pancreatic cancer cells. Mol Biol Cell. 2013;24(6):715-33.

29. Laing JG, Tadros PN, Westphale EM, Beyer EC. Degradation of connexin43 gap junctions involves both the proteasome and the lysosome. Exp Cell Res. 1997;236(2):482-92.

30. Musil LS, Le AC, VanSlyke JK, Roberts LM. Regulation of connexin degradation as a mechanism to increase gap junction assembly and function. J Biol Chem. 2000;275(33):25207-15.

31. Girao $\mathrm{H}_{1}$ Catarino S, Pereira P. Eps 15 interacts with ubiquitinated $\mathrm{C} \times 43$ and mediates its internalization. Exp Cell Res. 2009;315(20):3587-97.

32. Bejarano E, Girao H, Yuste A, Patel B, Marques C, Spray DC, Pereira P, Cuervo AM. Autophagy modulates dynamics of connexins at the plasma membrane in a ubiquitin-dependent manner. Mol Biol Cell. 2012;23(11):2156-69.
33. Colussi C, Rosati J, Straino S, Spallotta F, Berni R, Stilli D, Rossi S, Musso E, Macchi E, Mai A, et al. Nepsilon-lysine acetylation determines dissociation from GAP junctions and lateralization of connexin 43 in normal and dystrophic heart. Proc Natl Acad Sci U S A. 2011;108(7):2795-800.

34. Saez JC, Nairn AC, Czernik AJ, Spray DC, Hertzberg EL, Greengard P, Bennett MV. Phosphorylation of connexin 32, a hepatocyte gap-junction protein, by CAMP-dependent protein kinase, protein kinase $\mathrm{C}$ and Ca2+/calmodulindependent protein kinase II. European journal of biochemistry / FEBS. 1990; 192(2):263-73.

35. Abrams CK, Oh S, Ri Y, Bargiello TA. Mutations in connexin 32: the molecular and biophysical bases for the X-linked form of Charcot-Marietooth disease. Brain Res. 2000;32(1):203-14.

36. Ressot C, Gomes D, Dautigny A, Pham-Dinh D, Bruzzone R. Connexin32 mutations associated with $\mathrm{X}$-linked Charcot-Marie-tooth disease show two distinct behaviors: loss of function and altered gating properties. J Neurosci. 1998;18(11):4063-75.

37. Abrams CK, Islam M, Mahmoud R, Kwon T, Bargiello TA, Freidin MM Functional requirement for a highly conserved charged residue at position 75 in the gap junction protein connexin 32. J Biol Chem. 2013; 288(5):3609-19.

38. Yum SW, Kleopa KA, Shumas S, Scherer SS. Diverse trafficking abnormalities of connexin32 mutants causing CMTX. Neurobiol Dis. 2002;11(1):43-52.

39. Matsuyama W, Nakagawa M, Moritoyo T, Takashima H, Umehara F, Hirata K, Suehara M, Osame M. Phenotypes of X-linked Charcot-Marie-tooth disease and altered trafficking of mutant connexin 32 (GJB1). J Hum Genet. 2001; 46(6):307-13.

40. Abrams CK, Goman M, Wong S, Scherer SS, Kleopa KA, Peinado A, Freidin MM. Loss of coupling distinguishes GJB1 mutations associated with CNS manifestations of CMT1X from those without CNS manifestations. Sci Rep. 2017;7:40166.

41. Kleopa KA, Abrams CK, Scherer SS. How do mutations in GJB1 cause Xlinked Charcot-Marie-tooth disease? Brain Res. 2012;1487:198-205.

42. Abrams CK, Freidin MM, Verselis VK, Bennett MV, Bargiello TA. Functional alterations in gap junction channels formed by mutant forms of connexin 32: evidence for loss of function as a pathogenic mechanism in the X-linked form of Charcot-Marie-tooth disease. Brain Res. 2001;900(1):9-25.

43. Dodd R, Peracchia C, Stolady D, Torok K. Calmodulin association with connexin32-derived peptides suggests trans-domain interaction in chemical gating of gap junction channels. J Biol Chem. 2008;283(40):26911-20.

44. Omori Y, Yamasaki H. Gap junction proteins connexin32 and connexin43 partially acquire growth-suppressive function in HeLa cells by deletion of their C-terminal tails. Carcinogenesis. 1999;20(10):1913-8.

45. Locke D, Koreen IV, Harris AL. Isoelectric points and post-translational modifications of connexin26 and connexin32. FASEB J. 2006;20(8):1221-3.

46. Spagnol G, Al-Mugotir M, Kopanic JL, Zach S, Li H, Trease AJ, Stauch KL, Grosely R, Cervantes M, Sorgen PL. Secondary structural analysis of the carboxyl-terminal domain from different connexin isoforms. Biopolymers. 2016;105(3):143-62.

47. VanSlyke JK, Musil LS. Analysis of connexin intracellular transport and assembly. Methods San Diego, Calif. 2000;20(2):156-64.

48. VanSlyke JK, Musil LS. Biochemical analysis of connexon assembly. Methods in molecular biology Clifton, NJ. 2001;154:117-34.

49. Hertzberg EL, Gilula NB. Isolation and characterization of gap junctions from rat liver. J Biol Chem. 1979;254(6):2138-47.

50. Li M, Luo J, Brooks CL, Gu W. Acetylation of p53 inhibits its ubiquitination by Mdm2. J Biol Chem. 2002;277(52):50607-11.

51. lanari A, Gallo R, Palma M, Alesse E, Gulino A. Specific role for p300/CREBbinding protein-associated factor activity in E2F1 stabilization in response to DNA damage. J Biol Chem. 2004;279(29):30830-5.

52. Geng H, Liu Q, Xue C, David LL, Beer TM, Thomas GV, Dai MS, Qian DZ. HIF1alpha protein stability is increased by acetylation at lysine 709. J Biol Chem. 2012;287(42):35496-505.

53. Costantini $\mathrm{C}$, Ko MH, Jonas MC, Puglielli L. A reversible form of lysine acetylation in the ER and Golgi lumen controls the molecular stabilization of BACE1. The Biochemical journal. 2007:407(3):383-95.

54. Verdel A, Curtet S, Brocard MP, Rousseaux S, Lemercier C, Yoshida M, Khochbin S. Active maintenance of mHDA2/mHDAC6 histone-deacetylase in the cytoplasm. Curr Biol. 2000;10(12):747-9.

55. Bertos NR, Gilquin B, Chan GK, Yen TJ, Khochbin S, Yang XJ. Role of the tetradecapeptide repeat domain of human histone deacetylase 6 in cytoplasmic retention. J Biol Chem. 2004;279(46):48246-54. 
56. Hubbert C, Guardiola A, Shao R, Kawaguchi Y, Ito A, Nixon A, Yoshida M, Wang XF, Yao TP. HDAC6 is a microtubule-associated deacetylase. Nature. 2002:417(6887):455-8.

57. Kovacs JJ, Murphy PJ, Gaillard S, Zhao X, Wu JT, Nicchitta CV, Yoshida M, Toft DO, Pratt WB, Yao TP. HDAC6 regulates Hsp90 acetylation and chaperone-dependent activation of glucocorticoid receptor. Mol Cell. 2005; 18(5):601-7.

58. Zhang X, Yuan Z, Zhang Y, Yong S, Salas-Burgos A, Koomen J, Olashaw N, Parsons JT, Yang XJ, Dent SR, et al. HDAC6 modulates cell motility by altering the acetylation level of cortactin. Mol Cell. 2007;27(2):197-213.

59. Choudhary C, Kumar C, Gnad F, Nielsen ML, Rehman M, Walther TC, Olsen JV, Mann M. Lysine acetylation targets protein complexes and co-regulates major cellular functions. Science. 2009;325(5942):834-40.

60. Yang X-J, Seto E. Lysine acetylation: codified crosstalk with other posttranslational modifications. Mol Cell. 2008:31(4):449-61.

61. Saitoh M, Oyamada M, Oyamada Y, Kaku T, Mori M. Changes in the expression of gap junction proteins (connexins) in hamster tongue epithelium during wound healing and carcinogenesis. Carcinogenesis. 1997; 18(7):1319-28.

62. Temme A, Buchmann A, Gabriel HD, Nelles E, Schwarz M, Willecke K. High incidence of spontaneous and chemically induced liver tumors in mice deficient for connexin32. Curr Biol. 1997:7(9):713-6.

63. Zhao B, Zhao W, Wang Y, Xu Y, Xu J, Tang K, Zhang S, Yin Z, Wu Q, Wang X Connexin32 regulates hepatoma cell metastasis and proliferation via the p53 and Akt pathways. Oncotarget. 2015;6(12):10116-33.

64. Castro C, Gomez-Hernandez JM, Silander K, Barrio LC. Altered formation of hemichannels and gap junction channels caused by $\mathrm{C}$-terminal connexin-32 mutations. J Neurosci. 1999;19(10):3752-60.

65. Barrio LC, Castro C, Gomez-Hernandez JM. Altered assembly of gap junction channels caused by $\mathrm{COOH}$-terminal connexin32 mutants of CMTX. Ann N Y Acad Sci. 1999;883:526-9.

66. Ahmad S, Martin PE, Evans WH. Assembly of gap junction channels: mechanism, effects of calmodulin antagonists and identification of connexin oligomerization determinants. European journal of biochemistry / FEBS. 2001;268(16):4544-52.

67. Ray A, Katoch P, Jain N, Mehta PP. Dileucine-like motifs in the C-terminal tail of connexin32 control its endocytosis and assembly into gap junctions. J Cell Sci. 2018;131:5.

68. Receveur-Brechot V, Bourhis JM, Uversky VN, Canard B, Longhi S. Assessing protein disorder and induced folding. Proteins. 2006;62(1):24-45.

69. Stauch K, Kieken F, Sorgen P. Characterization of the structure and intermolecular interactions between the connexin 32 carboxyl-terminal domain and the protein partners synapse-associated protein 97 and calmodulin. J Biol Chem. 2012;287(33):27771-88.

70. Hertzberg EL, Van Eldik L: Interaction of calmodulin and other calciummodulated proteins with gap junctions. Methods Enzymol 1987, 139:445-454

71. Wang $X G$, Peracchia C. Positive charges of the initial C-terminus domain of CX32 inhibit gap junction gating sensitivity to CO2. Biophys J. 1997;73(2): 798-806.

Ready to submit your research? Choose BMC and benefit from:

- fast, convenient online submission

- thorough peer review by experienced researchers in your field

- rapid publication on acceptance

- support for research data, including large and complex data types

- gold Open Access which fosters wider collaboration and increased citations

- maximum visibility for your research: over $100 \mathrm{M}$ website views per year

At $\mathrm{BMC}$, research is always in progress.

Learn more biomedcentral.com/submissions 